\title{
Supramolecular assembly of high-density lipoprotein mimetic nanoparticles using lipid- conjugated core scaffolds
}

\author{
Stephen E. Henrich, ${ }^{\#}$ Bong Jin Hong, ${ }^{\&}$ Jonathan S. Rink, ${ }^{\#}$ SonBinh T. Nguyen, ${ }^{\&, \xi, \uparrow, *}$ and C. Shad Thaxton ${ }^{\#, \xi, \uparrow, \ddagger, *}$
}

${ }^{\#}$ Department of Urology, Feinberg School of Medicine; ${ }^{*}$ Simpson Querrey Institute for BioNanotechnology; and ${ }^{\dagger}$ Robert H. Lurie Comprehensive Cancer Center, Northwestern University, 303 E. Chicago Ave., Chicago, Illinois, 60611, United States.

${ }^{\&}$ Department of Chemistry and $\$$ International Institute for Nanotechnology, Northwestern University, 2145 Sheridan Rd., Evanston, Illinois, 60208, United States.

\section{Table of Contents}

S1. Materials and instrumentation $\quad S 1$

$\begin{array}{lr}\text { S2. Synthesis } & S 2\end{array}$

S3. Transmission electron microscopy, dynamic light scattering, and size exclusion chromatography $S 6$

S4. Circular dichroism $\quad$ S6

S5. Composition characterization $\quad S 6$

$\begin{array}{lr}\text { S6. Oligomerization assay } & S 7\end{array}$

$\begin{array}{ll}\text { S7. Radiolabeled cholesterol transport assays } & S 7\end{array}$

S8. NBD-cholesterol delivery experiments $\quad S 8$

$\begin{array}{ll}\text { S9. Lecithin:cholesterol acyltransferase (LCAT) activity assays } & S 8\end{array}$

$\begin{array}{ll}\text { S10. NF- } \mathrm{KB} \text { activity assays } & S 8\end{array}$

$\begin{array}{lr}\text { S11. Supplemental results and discussions } & S 9\end{array}$

$\begin{array}{lr}\text { S12. References } & S 15\end{array}$

\section{S1. Materials and instrumentation}

Unless otherwise stated, all reagents and reagent-grade solvents were purchased from Sigma-Aldrich (Milwaukee, WI) and used as received. All lipids- 1,2-dipalmitoyl-sn-glycero-3-phosphoethanolamine-N-dibenzocyclooctyl (DBCO PE) and 1,2-dipalmitoyl-sn-glycero-3-phosphocholine (DPPC)- and fluorescent cholesterol (22-( $N$-(7-Nitrobenz-2-Oxa-1,3Diazol-4-yl)Amino)-23,24-Bisnor-5-Cholen-3 $\beta$-Ol ((NBD)-cholesterol)), were obtained from Avanti Polar Lipids (Alabaster, AL). Monomeric apoA-I protein and lecithin:cholesterol acyltransferase (LCAT) protein were obtained from MyBioSource (San Diego, CA). Ultrapure deionized (DI) $\mathrm{H}_{2} \mathrm{O}(18.2 \mathrm{M} \Omega \cdot \mathrm{cm}$ resistivity) was obtained from a Millipore system (Milli-Q Biocel). Tetrakis(4-azidophenyl)methane ${ }^{1}$ and lipid phosphoramidite ${ }^{2}$ were synthesized according to previously published procedures.

The syntheses of hexynyl-functionalized DNA strands and DNA-lipid conjugates were carried out on an Expedite 8909 Nucleic Acid System. DNA products were purified and analyzed on an Agilent 1100 HPLC equipped with reverse-phase (RP) semi-preparative (Dynamax, $250 \times 10 \mathrm{~mm}$, Microsorb $300 \AA / 10 \mu \mathrm{m} / \mathrm{C} 18$, Agilent \# R083213C10) and analytical (Dynamax, $100 \times 4.6 \mathrm{~mm}$, Microsorb $100 \AA / 3 \mu \mathrm{m} / \mathrm{C} 18$, Agilent \# R0080200E3) columns, respectively. The coupling of hexynyl-functionalized DNA with tetrakis(4-azidophenyl)methane was carried out in a Thermomixer R 5355 (Eppendorf AG North America, Hauppauge, NY) instrument.

Absorption spectra of DNA materials were recorded on a Varian Cary 300 Bio UV-vis spectrophotometer (Varian, Inc., Palo Alto, CA) using a masked quartz cell (path length $=10 \mathrm{~mm}$, catalog \# 29B-Q-10-MS, Starna cells Inc., Atascadero, CA).

Negative stain transmission electron microscopy (TEM) images were acquired using a FEI Tecnai Spirit TEM operating at $80 \mathrm{kV}$, using 300-mesh carbon-coated copper grids (Electron Microscopy Services).

Dynamic light scattering (DLS) and zeta potential measurements were carried out on a Zetasizer Nano ZS (Malvern Instruments, Malvern, UK) equipped with a He-Ne laser (633 nm).

Size-exclusion chromatography (SEC) was carried out on a PSS Suprema column $(7.6 * 250 \mathrm{~mm}$ ) using an Agilent 1260 HPLC system equipped with UV-vis detector and connected to Wyatt Heleos II MALS and RI detectors. The eluent was PBS with $0.02 \mathrm{wt} \%$ sodium azide. The flow rate was $1.0 \mathrm{~mL} / \mathrm{min}$. The instrument was calibrated with polystyrene and BSA standards. Data was processed with Astra 6 software (Wyatt Technology Corporation, Santa Barbara, CA).

Confocal imaging was carried out with a Nikon A1R Spectral microscope. Flow cytometry was performed using a BD LSRFortessa cell analyzer.

Matrix-assisted laser desorption/ionization time-of-flight (MALDI-ToF) mass spectrometric data were collected as negative ions using the linear mode on a Bruker AutoFlex III MALDI-ToF mass spectrometer (Bruker Daltonics, Billerica, MA). The instrument was equipped with Smartbeam ${ }^{\mathrm{TM}}$ laser technology operated at 30-40\% power with a sampling speed of $10 \mathrm{~Hz}$. One thousand scans were averaged for each mass spectrum. Data from Agilent HPLC and Bruker MALDI-ToF instruments were processed using MestreNova software version 8.1.1-11591. 


\section{S2. Synthesis}

\section{a. Synthesis of DNA-PL4 cores}

a-1. Synthesis and purification of 9- and 18-SMDH4's. Small molecule-DNA hybrids (SMDHs) with 9 and 18 mer DNA arms (9- and 18-SMDH ${ }_{4}$ 's, respectively) were synthesized and purified according to a previously published procedure ${ }^{3}$ and DNA sequences used in this study are listed in the Table S1. To identify the different products that were formed in the SMDH preparation, an aliquot of the collected sample of crude SMDHs was first analyzed using an analytical RP-HPLC column (see Section S1) and a gradient method beginning with 95:5 v/v 0.1 M TEAA (aq):MeCN (TEAA (aq) = triethylammonium acetate, aqueous solution), and increasing to 60:40 v/v 0.1 M TEAA(aq):MeCN over 35 min (at a ramp of $+1 \mathrm{vol} \% \mathrm{MeCN} / \mathrm{min}$ ), with a flow rate of $1 \mathrm{~mL} / \mathrm{min}$. Then, the whole sample was subjected to purification using a semipreparative RP-HPLC column (see Section S1) and a gradient method beginning with 95:5 v/v 0.1 M TEAA (aq):MeCN and increasing to $60: 40 \mathrm{v} / \mathrm{v} 0.1 \mathrm{M} \mathrm{TEAA}(\mathrm{aq}): \mathrm{MeCN}$ over $70 \mathrm{~min}$ (at a ramp of $+0.5 \mathrm{vol} \% \mathrm{MeCN} / \mathrm{min}$, a slower gradient was employed here to ensure adequate separation of the peaks), with a flow rate of $3 \mathrm{~mL} / \mathrm{min}$. The identity of the collected $\mathrm{SMDH}_{4}$ product was confirmed by MALDI-ToF MS analysis (insets in Figures S1 and S2) and its purity was reassessed using analytical RP-HPLC (Figures S1 and S2) with the aforementioned analytical RP-HPLC solvent program.

a-2. Solid-phase synthesis and purification of DNA-phospholipid conjugates. Syntheses were carried out from the 3' direction using controlled pore glass (CPG) beads possessing $1 \mu$ mol of either adenine (Glen Research, dA-CPG \# 20-2001$10,(1000 \AA, 28 \mu \mathrm{mol} / \mathrm{g}))$ or thymine (Glen Research, dT-CPG \# 20-2031-10 (1000 $\AA, 27 \mu \mathrm{mol} / \mathrm{g})$ ) attached to the surface. The CPG beads were placed in a $1 \mu \mathrm{mol}$ synthesis column and 3'-phosphoramidites (Glen Research, dA-CE phosphoramidite \# 10-1000-C5, Ac-dC-CE phosphoramidite \# 10-1015-C5, dmf-dG-CE phosphoramidite \# 10-1029-C5, dT-CE phosphoramidite \# 10-1030-C5) were then added using the standard $1 \mu \mathrm{mol}$ protocol on an Expedite 8909 synthesizer to make the CPG-3'-ssDNA (see Table S1 for sequences). A lipid phosphoramidite was added to the $5^{\prime}$ end of ssDNA strand and then the beads were dried with a stream of dried nitrogen gas and placed in a vial containing aqueous fresh AMA solution ( $1 \mathrm{~mL}$ of a $1: 1 \mathrm{v} / \mathrm{v}$ mixture of $30 \mathrm{wt} \%$ aqueous ammonium hydroxide solution and $40 \mathrm{wt} \%$ aqueous methylamine solution). The vial was then capped and heated at $65{ }^{\circ} \mathrm{C}$ for $15 \mathrm{~min}$ to cleave DNA-lipid conjugates from the solid supports. The ammonia and methyl amine byproducts were then removed by passing a stream of dry nitrogen gas over the content of the vial until the characteristic ammonia smell disappears. The remaining liquid, which contains the crude DNA-lipid conjugates, was collected by pipette and the remaining beads were further extracted with ultrapure deionized water $(200 \mu \mathrm{L})$. The extract was combined with the initial solution of crude DNA-lipid conjugates (affording a total volume of $0.4 \mathrm{~mL}$ at the end) and filtered through a $0.45 \mu \mathrm{m}$ nylon syringe filter (Acrodisc ${ }^{\circledR} 13 \mathrm{~mm}$ syringe filter \# PN 4426T). The collected sample of crude product was subjected to purification using analytical RP-HPLC (Figures S3 and S4) and a gradient method beginning with 95:5 v/v 0.1 M TEAA (aq):MeCN (TEAA (aq) = triethylammonium acetate, aqueous solution), and increasing to 100\% $\mathrm{MeCN}$ over $50 \mathrm{~min}$ (at a ramp of $+1.9 \mathrm{vol} \% \mathrm{MeCN} / \mathrm{min}$ ), with a flow rate of $1 \mathrm{~mL} / \mathrm{min}$. The identity of the collected product was confirmed by MALDI-ToF analysis (insets in Figures S3 and S4) and its purity was verified by denaturing polyacrylamide gel electrophoresis (PAGE) (Figure S4).

a-3. Assembly of DNA-phospholipid conjugates and $\mathrm{SMDH}_{4}$. Equimolar mixtures of the as-prepared $\mathrm{SMDH}_{4}$ and its complementary DNA-lipid conjugate in TAMg buffer solution (40 mM Tris, $20 \mathrm{mM}$ acetic acid, and $7.5 \mathrm{mM} \mathrm{MgCl} 2 ; \mathrm{pH}$ 7.4) were added into $0.5 \mathrm{~mL}$ Eppendorf tubes. The resulting solutions were then heated to $90{ }^{\circ} \mathrm{C}$ in a heating block (Thermomixer R; Eppendorf, Hauppauge, NY) and kept there for 5 min to remove all initial DNA interactions. The power to the heating block was then turned off to allow the solution to slowly cool to rt over $3 \mathrm{~h}$ (for a typical cooling profile of this equipment, please see Fig. S16 in the SI for Yildirim, I.; Eryazici, I.; Nguyen, S. T.; Schatz, G. C. J. Phys. Chem. B 2014, 118, 23662376).

Table S1. List of DNA sequences of $\mathrm{SMDH}_{4}$ DNA arms and DNA-lipid conjugates used in this study.

\begin{tabular}{cl}
\hline DNA Length & DNA sequences $^{a}$ \\
\hline 9-SMDH & \\
18-SMDH & 3'-TCG GCT GGA-small molecule \\
9-DNA-lipid & 3'-TTG CTG AGT ATA ATT GTT-small molecule \\
18-DNA-lipid & 3'-TCC AGC CGA-lipid \\
\hline
\end{tabular}

${ }^{a}$ DNA sequences of $\mathrm{SMDH}_{4}$ DNA arms are complementary to those of DNA-lipid conjugates (i.e., 9-SMDH 4 to 9-DNA-lipid and 18-SMDH 4 to 18-DNA-lipid). 


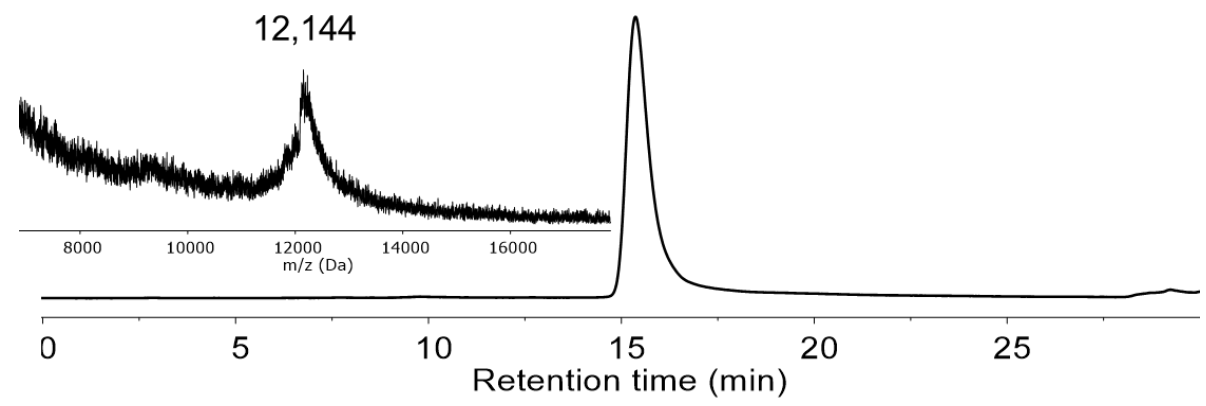

Figure S1. Analytical RP-HPLC trace of 9-SMDH 4 from the coupling reaction of the tetrakis(4-azidophenyl) methane with alkyne-functionalized 9-mer DNAs on the CPGs. The trace is the signal from the diode detector set at $260 \mathrm{~nm}$. Inset shows the MALDI-ToF spectrum of the pure product: $\mathrm{m} / \mathrm{z}=12,144$ (12,144.1 theoretical).

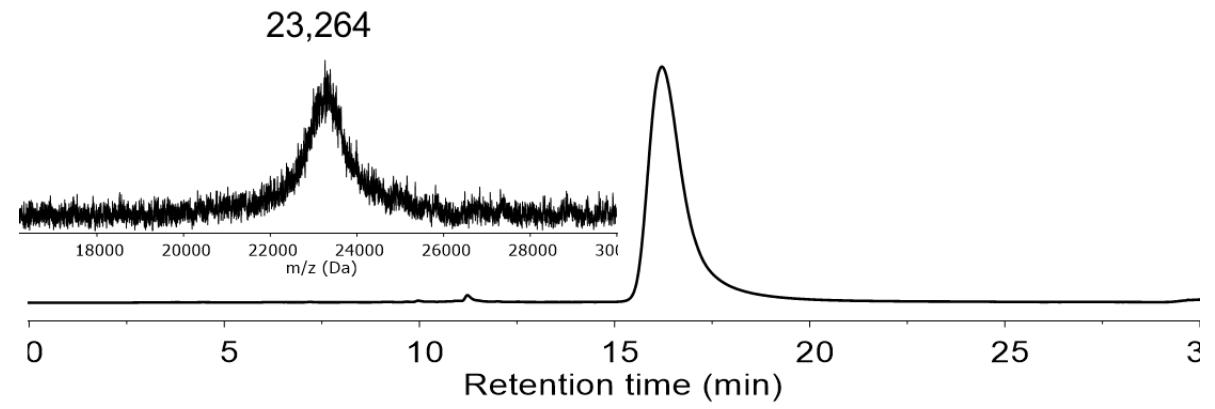

Figure S2. Analytical RP-HPLC trace of $18-\mathrm{SMDH}_{4}$ from the coupling reaction of the tetrakis(4-azidophenyl) methane with alkyne-functionalized 18-mer DNAs on the CPGs. The trace is the signal from the diode detector set at $260 \mathrm{~nm}$. Inset shows the MALDI-ToF spectrum of the pure product: $\mathrm{m} / \mathrm{z}=23,264$ (23,263.7 theoretical).

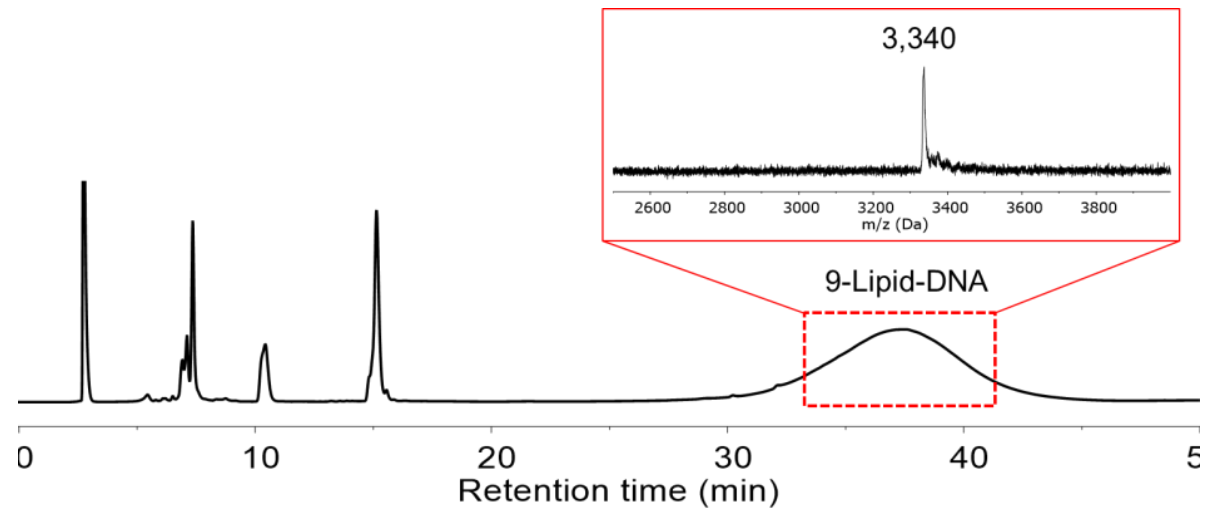

Figure S3. Semi-preparative RP-HPLC trace of crude 9-DNA-lipid. The trace is the signal from the diode detector set at $260 \mathrm{~nm}$. The pure 9-DNA-lipid at 33-42 min was isolated and identified by MALDI-ToF (Inset): $\mathrm{m} / \mathrm{z}=3,340$ (3,342.4 theoretical). 


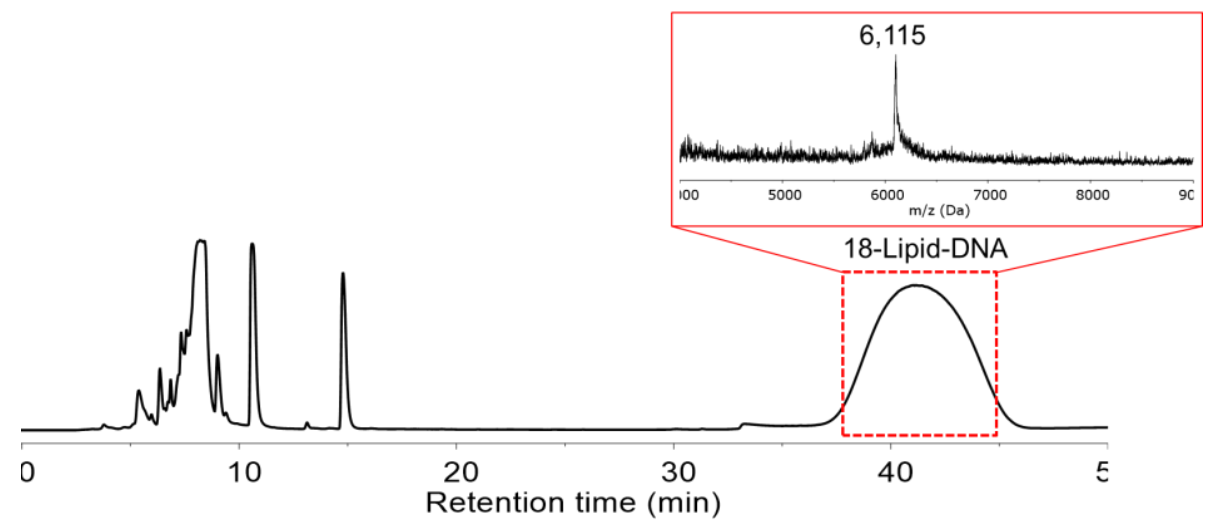

Figure S4. Semi-preparative RP-HPLC trace of crude 18-DNA-lipid. The trace is the signal from the diode detector set at $260 \mathrm{~nm}$. The pure 18-DNA-lipid at 38-45 min was isolated and identified by MALDI-ToF (Inset): $\mathrm{m} / \mathrm{z}=6,115$ $(6,118.2$ theoretical).

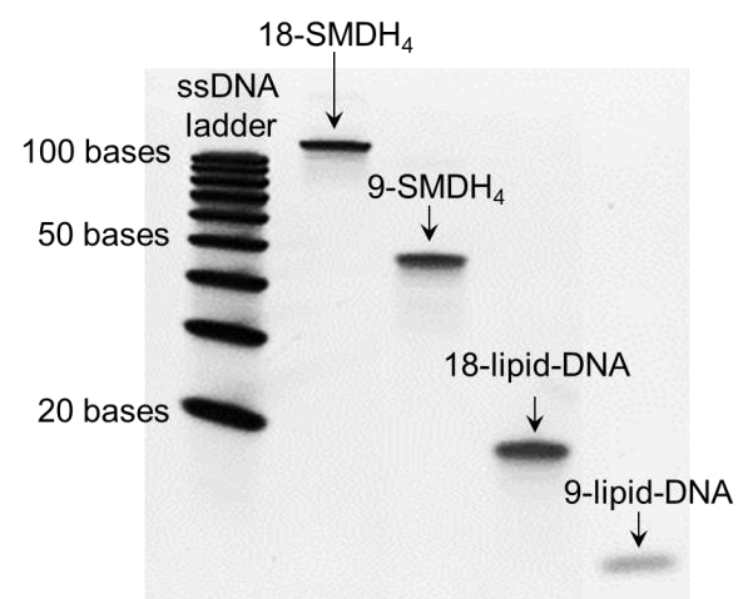

Figure S5. Denaturing PAGE-gel image (15\%, $7 \mathrm{M}$ Urea) of 9- and 18-SMDH 4 's and 9- and 18-DNA-lipid conjugates. The gel experiment was carried out in $1 \times$ TBE buffer at $180 \mathrm{~V}$ for $1 \mathrm{~h}$ and then the gels were stained with SYBR Gold (Thermo Fisher Scientific, Inc., Grand Island, NY) and their pictures were taken using a Typhoon 9400 (GE Healthcare, Pittsburgh, PA).

\section{b. Synthesis of PL4 core}
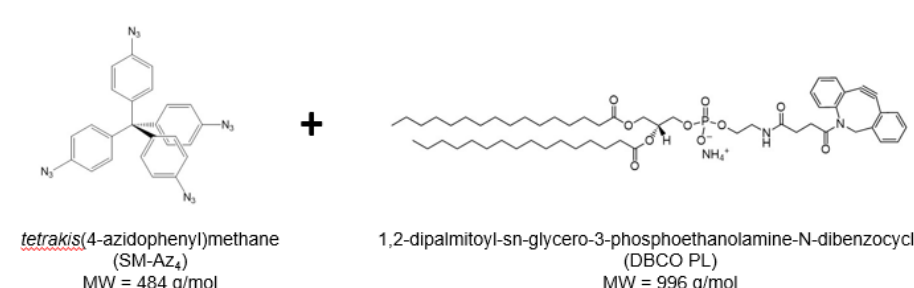

1,2-dipalmitoyl-sn-glycero-3-phosphoethanolamine-N-dibenzocycloocty (DBCO PL) $\mathrm{MW}=996 \mathrm{~g} / \mathrm{mo}$

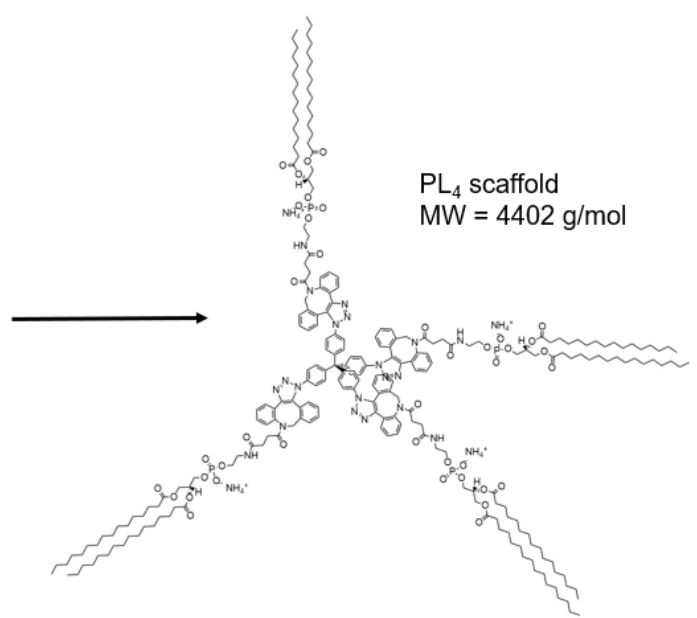

Figure S6. $\mathrm{PL}_{4}$ synthesis scheme. 
$\mathrm{PL}_{4}$ core materials were synthesized by copper-free click chemistry conjugation of 1,2-dipalmitoyl-sn-glycero-3phosphoethanolamine- $N$-dibenzocyclooctyl (DBCO PE) with a tetrahedral small molecule core (tetrakis(4azidophenyl)methane) with four terminal azides (Figure S6). In a typical reaction, the DBCO PE and tetrakis(4azidophenyl)methane were each dissolved at $0.1 \mathrm{wt} \%$ in $N, N$-dimethylformamide (DMF, Sigma Aldrich) and mixed at a 10:1 molar ratio of DBCO PE to tetrakis(4-azidophenyl)methane in DMF. The reaction mixture was subjected to three rounds of alternating vortexing and bath sonication, and was then allowed to react at room temperature under vortex for $24 \mathrm{~h}$. HPLC and electrospray ionization mass spectrometry (Figure S7) was then used to characterize the resulting reaction mixture. As Figure S7 only show a single species at the right mass for $\mathrm{PL}_{4}$, we conclude that there is no partially coupled product $\left(\mathrm{PL}_{3}\right.$, $\mathrm{PL}_{2}$, etc.) and use the reaction mixture for the assembly step. As the assembly step (see Section S2c below) involves adding a large excess of DPPC lipids, there is no need to separate the excess DBCO PE molecule from the $\mathrm{PL}_{4}$ core prior to its use in the assembly.

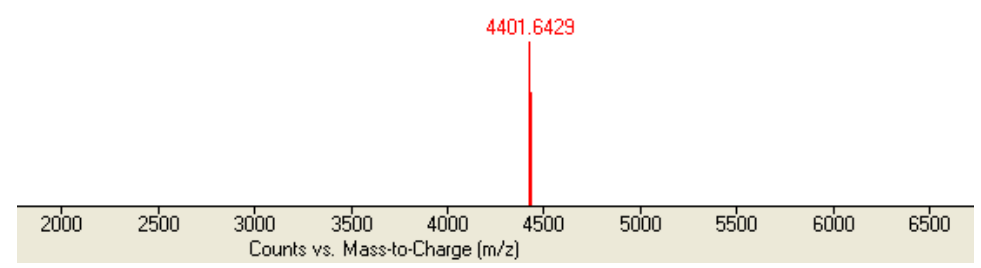

Figure S7. Electrospray ionization mass spectrum of $\mathrm{PL}_{4}$ core. Product $\mathrm{m} / \mathrm{z}=4401.6$ (Theoretical: 4401.7).

c. LC HDL NP assembly. Nanoparticle assembly was carried out by first preparing 1,2-dipalmitoyl-sn-glycero-3phosphocholine (DPPC) liposomes. DPPC was dissolved at $0.1 \mathrm{wt} \%$ in chloroform in $5 \mathrm{~mL}$ glass vials. A thin film was then generated by evaporating the solvent with $\mathrm{N}_{2}$ gas. The film was further dried under reduced pressure in a desiccator for $>2 \mathrm{~h}$. Liposomes were then generated by resuspending the thin film in phosphate-buffered saline (PBS, $10 \mathrm{mM}$ phosphate and $137 \mathrm{mM} \mathrm{NaCl}, \mathrm{pH}=7.4$ ) at a DPPC concentration of $1 \mathrm{mM}$ and then subjecting to alternating bath sonication and vortexing. For $\mathrm{PL}_{4}$ HDL NPs, the $\mathrm{PL}_{4}$ core scaffold was prepared by generating a thin film from a $0.1 \mathrm{wt} \%$ solution in DMF by evaporating the solvent with $\mathrm{N}_{2}$ gas. For DNA-PL 4 HDL NPs, the core scaffolds were prepared as a solution in TAMg buffer (40 mM Tris, $20 \mathrm{mM}$ acetic acid, and $7.5 \mathrm{mM} \mathrm{MgCl}_{2}$; $\mathrm{pH}=7.4$ ) due to the improved water solubility of the core imparted by the oligonucleotides.

To initiate particle assembly, the non-scaffold nanoparticle components were then added sequentially to the core scaffolds. In a typical assembly, DPPC (20 nmol from a $1 \mathrm{mM}$ suspension in PBS) was combined with the lipid conjugate core scaffold (either $\mathrm{PL}_{4}$ or DNA-PL $4,2 \mathrm{nmol}$ from a thin film $\left(\mathrm{PL}_{4}\right)$ or a $1 \mathrm{mM}$ suspension in PBS (DNA-PL4)), followed by the addition of apoA-I ( $4 \mathrm{nmol}$ from a $1 \mathrm{mg} / \mathrm{mL}$ suspension in PBS). This combined suspension was then diluted in PBS to a final core concentration $^{\mathrm{i}}$ of $10 \mu \mathrm{M}$ in PBS. Next, the resulting suspension was subjected to three rounds of alternating bath sonication ( $90 \mathrm{~s}$ ON, $30 \mathrm{~s} \mathrm{OFF)} \mathrm{and} \mathrm{vortexing,} \mathrm{and} \mathrm{allowed} \mathrm{to} \mathrm{relax} \mathrm{on} \mathrm{ice} \mathrm{for} 30 \mathrm{~min}$. The particles were then filtered and concentrated using spin columns (MilliPore; $0.5 \mathrm{~mL} 50 \mathrm{kDa}$ MWCO). The column was first rinsed in PBS for $10 \mathrm{~min}$ at $10,000 \mathrm{~g}$ at $4^{\circ} \mathrm{C}$, prior to three rounds of spin filtration of the particles under the same conditions. An aliquot of PBS $(500 \mu \mathrm{L})$ was added to the column after each spin. After each round of filtration, the particles were centrifuged by desktop centrifugation ${ }^{\text {ii }}$ to remove aggregates, if any. After the final round of filtration, the small volume of concentrated particles $(\sim 20 \mu \mathrm{L})$ was diluted to 100-200 $\mu \mathrm{L}$ in PBS and the protein concentration was determined by bicinchoninic acid assay (BCA), with spectroscopic measurement of absorbance at $562 \mathrm{~nm}$ after incubation with BCA reagents at $37^{\circ} \mathrm{C}$ for $30 \mathrm{~min}$. The particles were then either used immediately or placed at $4{ }^{\circ} \mathrm{C}$ for short-term storage. For all downstream assays, the concentration of LC HDL NPs was determined by BCA quantification of protein; and protein concentration was held constant across all groups.

\footnotetext{
i As a further clarification, "core concentration" is used as a convenient term that refers to the concentration of the tetrahedral core unit in $\mathrm{PL}_{4}$ and DNA-PL4 compounds. For instance, batches of particles were often made at a scale of 1-3 nmol of the tetrahedral core. Adding $1 \mathrm{nmol}$ of this core-containing compound into $100 \mu \mathrm{L}$ of buffer solution yields a final solution with $10 \mu \mathrm{M}$ core concentration. Aliquots of this stock solution would then be added to the treatment of cells, etc., to yield a mixture at the desired concentrations, often $\sim 100 \mathrm{nM}$.

We note that all treatments were held at a protein concentration that is constant across all samples. The core concentration of DNA-PL4 was determined directly using UV-vis spectroscopy and Beer's Law, upon knowing the molar extinction coefficient of the DNA. The protein concentration was determined via BCA, and a ratio of core to protein could then be determined.

ii While no aggregates were macroscopically visible; this step was included as a conservative measure for two reasons: 1) In earlier assembly attempts, we observed visible aggregates formed after thin film rehydration and sonication, particularly when we used very high stoichiometries of phospholipids; these aggregates were then removed by benchtop centrifugation. 2) This step was previously reported in the synthesis of a related self-assembled HDL mimic using apoA-I mimetic peptides, which has some similarities to our assembly process. ${ }^{4}$ Based on TEM imaging of the products from earlier assembly attempts, we believe these aggregates were likely multilamellar vesicles that were formed from excess phospholipids that were not incorporated into the desired spherical HDL particles. This is supported by the observation that when higher stoichiometries of phospholipids were used in these earlier assembly attempts, more aggregates were seen, while this was not the case when higher apoA-I or core stoichiometries were attempted.
} 
d. Preparation of controls for TEM. Control samples were prepared to investigate the LC HDL NP assembly process, and its dependence on the lipid conjugated core scaffold and apoA-I. Core scaffold + lipids without apoA-I controls were prepared by first making DPPC liposomes as described above (Section S2c). DPPC liposomes were then added to core scaffolds at the same concentration and molar ratio as in LC HDL NPs, with PL4 scaffolds thin filmed and DNA-PL4 scaffolds in aqueous buffer. The mixtures were then subjected to three rounds of alternating sonication and vortexing, and were filtered and concentrated through $50 \mathrm{kDa}$ MWCO spin columns as above. ApoA-I + DPPC alone controls were assembled in an identical manner, in the absence of core scaffolds but with addition of apoA-I. Core scaffold alone controls were subjected to the same sonication and filtering process, without addition of DPPC or apoA-I.

e. Synthesis of Au HDL NPs. Au HDL NPs were synthesized and purified as previously reported by the Thaxton group. ${ }^{5}$ In the indicated reference, the synthesis and purification protocol can be found in the Materials and Methods section entitled "Synthesis of fmHDL". We note that the Au HDL NPs terminology used in the current work refers to the fmHDLs assembled using ordinary apoA-I, not "apoA-I-SH", which was also being investigated therein.

\section{S3. Transmission electron microscopy, dynamic light scattering, and size exclusion chromatography}

a. Negative stain transmission electron microscopy. For grid preparation, samples were prepared at a concentration of $500 \mathrm{nM}-2 \mu \mathrm{M}$ protein in PBS, dropcast on UV-treated carbon-coated copper 300-mesh grids (Electron Microscopy Services) and air dried in a chemical fume hood. The grids were washed twice with PBS, stained twice with $2 \%$ uranyl acetate for 20 sec, then washed three times with PBS and air dried prior to imaging. Imaging was conducted using a FEI Tecnai Spirit TEM operating at $80 \mathrm{kV}$.

b. Dynamic light scattering (DLS). DLS and zeta potential measurements were carried out on a Zetasizer Nano ZS (Malvern Instruments, Malvern, UK) equipped with a He-Ne laser $(633 \mathrm{~nm})$. Non-invasive backscatter method (detection at $173^{\circ}$ scattering angle) was used. Correlation data were fitted, using the method of cumulants, to the logarithm of the correlation function, yielding the diffusion coefficient $(D)$. The hydrodynamic diameters $\left(D_{\mathrm{H}}\right)$ of the particles were calculated using $D$ and the Stokes-Einstein equation $\left(D_{\mathrm{H}}=k_{B} T / 3 \pi \eta D\right.$, where $k_{B}$ is the Boltzmann constant, $T$ is the absolute temperature, and $\eta$ is the solvent viscosity $\left(\eta=0.8872 \mathrm{cP}\right.$ for water)). The polydispersity index (PDI) - represented as $2 c / b^{2}$, where $b$ and $c$ are first- and second-order coefficients, respectively, in a polynomial of a semi-log correlation function — was calculated by cumulants analysis. Size distribution of particles was obtained by non-negative least squares (NNLS) analysis. ${ }^{6}$ Samples were prepared in distilled water or PBS, typically at $200 \mathrm{nM}$ protein concentration. For each sample, three measurements were acquired with ten runs per measurement.

c. Size exclusion chromatography (SEC). SEC analysis was performed on PSS Suprema column $7.6 * 250 \mathrm{~mm}$ using Agilent 1260 HPLC system equipped with UV detector and connected to Wyatt Heleos II MALS and RI detectors. Flow rate was $1 \mathrm{~mL} / \mathrm{min}$ using PBS with $0.02 \mathrm{wt} \%$ sodium azide as an eluent. The instrument was calibrated with polystyrene and BSA standards. Data was processed with Astra 6 software (Wyatt Technology Corporation, Santa Barbara, CA).

\section{S4. Circular dichroism}

Circular dichroism was carried out using a JASCO J-815 CD spectrometer. All samples were diluted to $75 \mu \mathrm{g} / \mathrm{mL}$ protein in distilled water. Spectra were derived from three accumulations of a single sample. Secondary structure data was acquired using CDPro software package running the CONTIN analysis algorithm. Three distinct analyses were performed using different soluble protein reference sets. The values reported in Table 1 reflect the mean \pm SEM results of these three analyses.

The CD spectra of the DNA-PL 4 conjugates alone exclusively exhibited circular dichroism peaks at $\sim 260 \mathrm{~nm}$, which is typical of nucleic acids, with no signal in the low-UV regions where alpha helicity, beta sheet, or turn content is observed for apoA-I-containing particles.

\section{S5. Composition characterization}

a. Protein quantification. To quantify protein content of nanoparticles and native HDL, we used a commercially available bicinchoninic acid (BCA) assay (Thermo Fisher) per the manufacturer's instructions. Briefly, we generated a protein standard curve by diluting bovine serum albumin (BSA) samples from $0.125-2 \mathrm{mg} / \mathrm{mL}$ into a final volume of $80 \mu \mathrm{l}$ per well in 96-well plates using BCA reagent solution. Nanoparticle samples were diluted in the same manner; standards and samples were diluted by a factor of 40 . Standards were plated in duplicate and samples were plated in triplicate. Plates were incubated for $30 \mathrm{~min}$ at $37^{\circ} \mathrm{C}$ and then absorbance at $562 \mathrm{~nm}$ was measured using a Synergy plate reader.

b. Phospholipid quantification. Phospholipid content of nanoparticles and native HDL was quantified using a colorimetric Phospholipid Assay Kit (Sigma-Aldrich) per the manufacturer's instructions. Briefly, a phospholipid standard calibration curve was prepared with a 15-200 $\mu \mathrm{M}$ range via serial dilution. Samples were serially diluted in PBS to obtain 
one or more dilutions within the range of the standard curve. ${ }^{\text {iii }}$ Samples and standards were then incubated with the enzyme reaction mixture for $30 \mathrm{~min}$ at $\mathrm{rt}$ and then absorbance at $572 \mathrm{~nm}$ was determined using a Synergy plate reader.

c. Cholesterol, Cholesteryl ester, and Core quantifications. Cholesterol and cholesteryl ester concentrations were determined using an Amplex Red Cholesterol Assay (ThermoFisher) per the manufacturer's instructions. Briefly, cholesterol standard curves were prepared in kit-provided aqueous buffer from $8 \mu \mathrm{g} / \mathrm{mL}$ to $125 \mathrm{ng} / \mathrm{mL}$. Two sets of samples were prepared in triplicate and diluted into kit-provided aqueous buffer. Two reaction mixtures were then prepared containing hydrogen peroxide, resorufin, and the enzymes horseradish peroxidase, cholesterol oxidase, with or without cholesterol esterase to enable quantification of both free cholesterol and cholesteryl esters. One set of samples was then incubated with reaction mixture containing cholesterol esterase, and the other set was incubated with reaction mixture without cholesterol esterase. Microplates were then incubated at $37{ }^{\circ} \mathrm{C}$ for $1 \mathrm{~h}$ or until fluorescent signal began to decline. The core concentration of

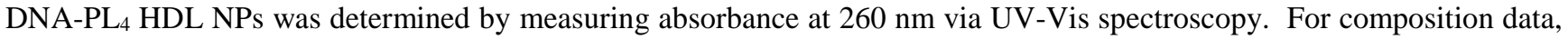
the $\mathrm{PL}_{4}$ core concentration was estimated using the experimentally determined core:protein molar ratio obtained for DNA$\mathrm{PL}_{4}$ particles. Composition of Au HDL NPs was reported from previously published work. ${ }^{5}$

\section{S6. Oligomerization assay}

a. Preparation of cross-linked particle and protein samples. The cross-linking agent bis(sulfosuccinidimidyl)suberate (BS3) (Sigma Aldrich) was used to stabilize any higher order oligomerization states of apoA-I in LC HDL NPs upon assembly, prior to detection via immunoblot. The method used here was adapted from a previously reported protocol ${ }^{5}$. LC HDL NPs were prepared as described above and diluted to $50 \mu \mathrm{g} / \mathrm{mL}$ protein in PBS. BS3 cross-linking agent was then added to LC HDL NPs for a final BS3 concentration of $2.5 \mathrm{mM}$, and the reaction was allowed to proceed for 30 min at room temperature. To produce an apoA-I oligomer ladder, lipid-free pure apoA-I (MyBioSource) was dialyzed in PBS, and then subjected to cross-linking with BS3 $(0.25 \mathrm{mM})$ at elevated protein concentration $(500 \mu \mathrm{g} / \mathrm{mL})$ for $4 \mathrm{~h}$ at room temperature. $0.5 \mathrm{M}$ Tris base was used to stop the cross-linking reactions (45 $\mathrm{mM}$ final).

b. apoA-I immunoblot. BioRad apparatuses were used for gel electrophoresis and protein transfer. Pre-cast 4-20\% polyacrylamide gels (MiniProtean TGX, BioRad) were used for separation. Protein transfer to polyvinylidine fluoride (PVDF) membrane was performed using Tris-Glycine buffer with 20 vol \% methanol. PVDF membrane was then rinsed in TBS and blocked in $5 \mathrm{wt} \%$ nonfat dry milk for $1 \mathrm{~h}$ at $\mathrm{rt}$. Primary antibody (rabbit anti-apoAI, Abcam) was added to the membrane at 1:1000 dilution in $5 \mathrm{wt} \%$ nonfat dry milk, and incubated at $4{ }^{\circ} \mathrm{C}$ overnight. The membrane was then washed in TBS-Tween $(0.1 \%)$ three times for $10 \mathrm{~min}$ each. Secondary antibody (goat anti-rabbit HRP, BioRad) was then added at 1:2000 dilution in $5 \mathrm{wt} \%$ nonfat dry milk. The membrane was then washed three times in TBS-Tween for ten minutes each, and then bathed in electrochemiluminescence substrate solution for $1 \mathrm{~min}$, and exposed to autoradiography film for 10-90 sec for optimal exposure duration and developed (Figure S12).

\section{S7. Radiolabeled Assays}

a. Efflux assays. For efflux experiments, we used the gold-standard assay in the field, efflux of tritium-labeled cholesterol $\left(\left[{ }^{3} \mathrm{H}\right]\right.$-chol) from J774 macrophages. J774 macrophages were cultured for at least two passages prior to seeding at 150,000 cells per well in 24 well plates in RPMI, 10\% fetal bovine serum (FBS), $1 \%$ penicillin-streptomycin (PenStrep) on Day 1. Ethanol stocks of $\left[{ }^{3} \mathrm{H}\right]$-chol were handled under sterile conditions. $\left[{ }^{3} \mathrm{H}\right]$-chol stocks were evaporated, redissolved in ethanol $(1 \mathrm{~mL})$ and incubated at $37{ }^{\circ} \mathrm{C}$ for $60 \mathrm{~min}$. The solution was then evaporated again and redissolved in ethanol (50 $\left.\mu \mathrm{L}\right)$ and incubated at $37{ }^{\circ} \mathrm{C}$ for $30 \mathrm{~min}$. Heat-inactivated FBS (Corning, NY) (1.5 mL) was then added to the $\left[{ }^{3} \mathrm{H}\right]$-chol solution and the resulting mixture was incubated at $4{ }^{\circ} \mathrm{C}$ overnight.

On Day 2, serum-free RPMI with $1 \%$ PenStep and $2 \mu \mathrm{g} / \mathrm{mL}$ Sandoz (Sigma-Aldrich, St. Louis, MO) was added to the $\left[{ }^{3} \mathrm{H}\right]$-chol-containing FBS to yield a final labeling media comprising $\left[{ }^{3} \mathrm{H}\right]$-chol $(2 \mu \mathrm{Ci} / \mathrm{mL}), 5$ vol \% FBS in RPMI. Note that Sandoz is an ACAT inhibitor used to prevent esterification of $\left[{ }^{3} \mathrm{H}\right]$-chol. Media was aspirated from 24 well plates and 500 $\mu \mathrm{L}$ of $\left[{ }^{3} \mathrm{H}\right]$-chol labeling media was added (1 uCi per well). Labeling was allowed to proceed for $24 \mathrm{~h}$.

On Day 3, labeling media was removed, cells were washed twice with MEM, $25 \mu \mathrm{M}$ HEPES, and upregulation media (RPMI, 1\% PenStrep, $300 \mu \mathrm{M}$ cAMP, $2 \mu \mathrm{g} / \mathrm{mL}$ Sandoz, 1\% BSA) was added to upregulate the canonical cholesterol efflux receptor ABCA1. (Note: for cAMP(-) efflux assays (Figure 4d), this media was added without cAMP in order to investigate SR-B1-dependent efflux.) Upregulation was allowed to proceed for $24 \mathrm{~h}$ prior to addition of efflux media. Efflux samples containing nanoparticles and controls were prepared in serum-free media (MEM, $25 \mu \mathrm{M}$ HEPES, 1\% PenStrep) to reduce non-specific $\left[{ }^{3} \mathrm{H}\right]$-chol efflux by serum cholesterol carriers. Cells were washed twice in MEM, $25 \mu \mathrm{M}$ HEPES and efflux

iii As an example calculation, an initial stock solution that contains $20 \mathrm{nmol}$ of DPPC in a volume of $100 \mu \mathrm{L}$ has a DPPC concentration of $200 \mu \mathrm{M}$. After particle synthesis and filtration, dilution and some DPPC loss occurred, reducing the final DPPC concentrations to the $100-200 \mu \mathrm{M}$ range, which falls in the range detected by the assay kit (range $=3-200 \mu \mathrm{M}$ ). 
media was added to each well according to the treatment regimen. Efflux was allowed to proceed for $4 \mathrm{~h}$. Efflux media was then removed, vacuum filtered, and added to $3 \mathrm{~mL}$ UltimaGold scintillation fluid for scintillation counting. A separate triplicate cohort of $\left[{ }^{3} \mathrm{H}\right]$-chol-loaded macrophages were washed, air dried, and incubated at room temperature in isopropanol to extract $\left[{ }^{3} \mathrm{H}\right]$-chol as a measure of total cholesterol at $\mathrm{t}=0$ at the beginning of efflux.

A PBS treated control cohort was used as a baseline, and the counts obtained for these samples were then subtracted from experimental groups to obtain baseline-corrected counts. Efflux percentages were then calculated as ratios of baselinecorrected counts for efflux media to counts for $\mathrm{t}=0$ macrophages, indicating the fraction of $\left[{ }^{3} \mathrm{H}\right]$-chol which was removed from cells over the course of $4 \mathrm{~h}$ treatment not due to diffusion alone. Protein concentration was held constant across all samples at $200 \mathrm{nM}$ for all experiments with the exception of dose-dependence studies.

b. Tandem efflux-influx assays. For efflux-influx experiments, efflux from $\mathbf{J} 774$ cells was conducted identically as above (Section 7a). Hepatocytes (HepG2 cells) were plated at 100,000 cells/well in DMEM, 10\% FBS, $1 \%$ PenStrep in 24 well plates on Day 3. On Day 4, immediately after 4 h of efflux, HepG2 cells were washed twice in serum-free MEM, $25 \mu \mathrm{M}$ HEPES, and then efflux media from J774 macrophages was removed and added directly to HepG2 cells. Influx was allowed to proceed for $4 \mathrm{~h}$ prior to harvesting. Influx media supernatant was then collected and processed identically as efflux media described above. [ ${ }^{3} \mathrm{H}$ ]-chol was then extracted from HepG 2 cells and $\mathrm{J} 774$ cells by incubating in $500 \mu \mathrm{L}$ isopropanol for $4 \mathrm{~h}$ at $\mathrm{rt}$, sealed in Parafilm. [ $\left.{ }^{3} \mathrm{H}\right]$-chol-containing isopropanol was then collected, evaporated, and redissolved in xylene prior to addition to UltimaGold for scintillation counting.

\section{S8. NBD-cholesterol delivery experiments}

a. Confocal microscopy. HepG2 cells were cultured in Dulbecco's Modified Eagle's Medium (DMEM) containing 10\% FBS and 1\% PenStrep. One day prior to treatment, cells were plated at 100,000 cells/well in 24 well plates on top of glass coverslips. On the day of treatment, cells were washed three times with PBS and fresh media containing $5 \mu \mathrm{g} / \mathrm{mL}$ NBDcholesterol was then added to each to each well with or without a delivery agent according to treatment regimen. Uptake was allowed to proceed for $30 \mathrm{~min}$ when the cells were fixed and prepared for confocal microscopy. Cells were fixed in $4 \%$ PFA for $10 \mathrm{~min}$ at rt. Cells were then washed three times in PBS, stained with DAPI (300 nM in PBS) for 5 min, and washed two more times in PBS. Coverslips were then mounted on glass slides, and allowed to seal at rt for at least $24 \mathrm{~h}$ prior to imaging. Confocal microscopy was performed using a Nikon A1R Spectral, and image processing was conducted with Nikon Elements and Fiji software.

b. Flow cytometry. HepG2 cells were plated at 200,000 cells/well in 24-well plates one day prior to treatment. On the day of treatment, cells were washed three times with PBS and fresh media containing $5 \mu \mathrm{g} / \mathrm{mL}$ NBD-cholesterol was then added to each to each well with or without a delivery agent according to treatment regimen. Uptake was allowed to proceed for $30 \mathrm{~min}$ prior to harvesting. Cells were then trypsinized, neutralized in serum-containing media, and centrifuged at $300 \mathrm{x}$ $g$ for 6 min to pellet the cells. Cells were resuspended in PBS containing 2\% bovine serum albumin (BSA) and then subjected to flow cytometry using a BD LSRFortessa cell analyzer (BD Biosciences). Analysis was performed using FlowJo software. Events were gated to exclude cellular debris and aggregates prior to quantification of NBD-chol positivity.

\section{S9. Lecithin cholesterol acyl transferase (LCAT) activity assays}

LC HDL NPs and Au HDL NPs (250 nM) suspended in PBS were incubated with LCAT (10 nM) and free cholesterol $(100 \mu \mathrm{g} / \mathrm{mL})$ in PBS at $37{ }^{\circ} \mathrm{C}$ for $15 \mathrm{~h}$ in a ThermoMixer shaking at $300 \mathrm{rpm}$. Samples were then centrifuged three times at $10,000 \mathrm{~g}$ for $10 \mathrm{~min}$ through a $50 \mathrm{kDa}$ spin column to remove excess unbound cholesterol. Samples were then diluted 100 times in 1× Reaction Buffer prior to quantification with Amplex Red Cholesterol Assay (Thermo Fisher). Amplex Red Cholesterol Assay was performed per manufacturer's instructions. Briefly, a cholesterol standard curve was prepared by serially diluting cholesterol in kit-provided aqueous buffer from $8 \mu \mathrm{g} / \mathrm{mL}$ to $125 \mathrm{ng} / \mathrm{mL}$ and adding $50 \mu \mathrm{l}$ to a 96 -well blackbottom microplate. $50 \mu \mathrm{l}$ of sample were also added to each well of the microplate in triplicate. Two sets of Amplex Red reaction mix were prepared, with and without cholesterol esterase. $50 \mu \mathrm{l}$ of Amplex Red reaction mix were then added to each well. Microplates were incubated at $37^{\circ} \mathrm{C}$ for $1 \mathrm{~h}$ or until fluorescent signal began to decline.

\section{S10. NF- $\mathrm{kB}$ activity assays}

For NF- $\kappa$ B activity experiments, THP1-Dual cells were used in conjunction with a QUANTI-Blue secreted embryonic alkaline phosphatase (SEAP) detection kit (Invivogen). THP1-Dual cells were cultured in suspension in RPMI with 10\% FBS and passaged at least twice prior to use in experiments. THP1-Dual cells were plated at 100,000 cells per well in 96 well plates. Lipopolysaccharide (LPS) $(5 \mathrm{ng} / \mathrm{mL})$ was used to stimulate NF- $\mathrm{KB}$ activity. Experimental wells were treated with LPS $1 \mathrm{~h}$ prior to addition of nanoparticles or controls. Cells were then incubated with particles or controls for $24 \mathrm{~h}$ prior to detection. QUANTI-Blue solution was prepared by dissolving the contents of the packet in endotoxin-free water and 
incubating at $37{ }^{\circ} \mathrm{C}$ for $30 \mathrm{~min}$. QUANTI-Blue solution $(180 \mu \mathrm{L})$ was added to each well in 96 -well plates. THP1-Dual cells supernatant $(20 \mu \mathrm{L})$ was then added to QUANTI-Blue solution, and the plate was incubated at $37{ }^{\circ} \mathrm{C}$ for $2-4 \mathrm{~h}$. SEAP levels were the quantified by detecting absorbance at $650 \mathrm{~nm}$ using a Synergy plate reader.

We note in passing that the high activity of the DNA-PL 4 HDL NP particles is unlikely to be due to apoA-I desorption, despite apoA-I's proclivity for exchange, particularly given the significantly enhanced activity of DNA-PL 4 particles over equimolar free apoA-I controls in radiolabeled influx studies, cholesterol delivery studies (NBD-chol), and NF-кB suppression studies, with control experiments showing the core of the particle to be inert.

\section{S11. Supplemental results and discussions}

a. Negative stain TEM of PL4 HDL NPs, 18-DNA-PL4 scaffolded assemblies, and controls

Negative stain TEM of LC HDL NPs and controls was performed as described above (Section S3).
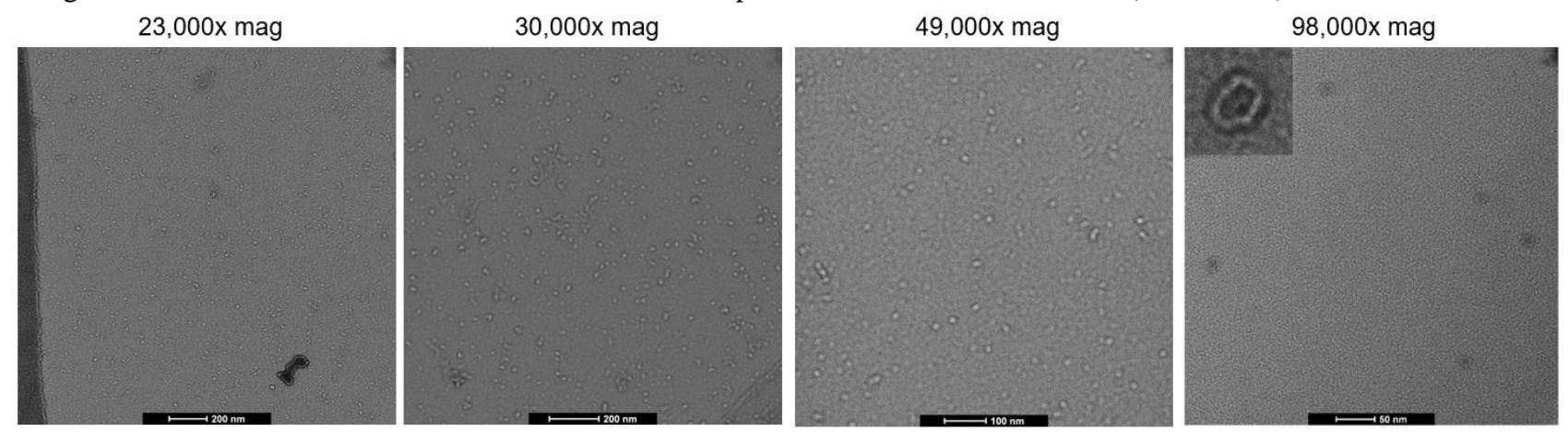

Figure S8. Ultrastructural characterization of $\mathrm{PL}_{4}$ HDL NPs via negative stain TEM. Imaging was performed with FEI Tecnai Spirit TEM. Inset (far right panel) is under 120,000× magnification. Scale bars labeled on each image, from 50-200 $\mathrm{nm}$. TEM diameter was determined to be $10 \pm 2 \mathrm{~nm}$ using ImageJ software.
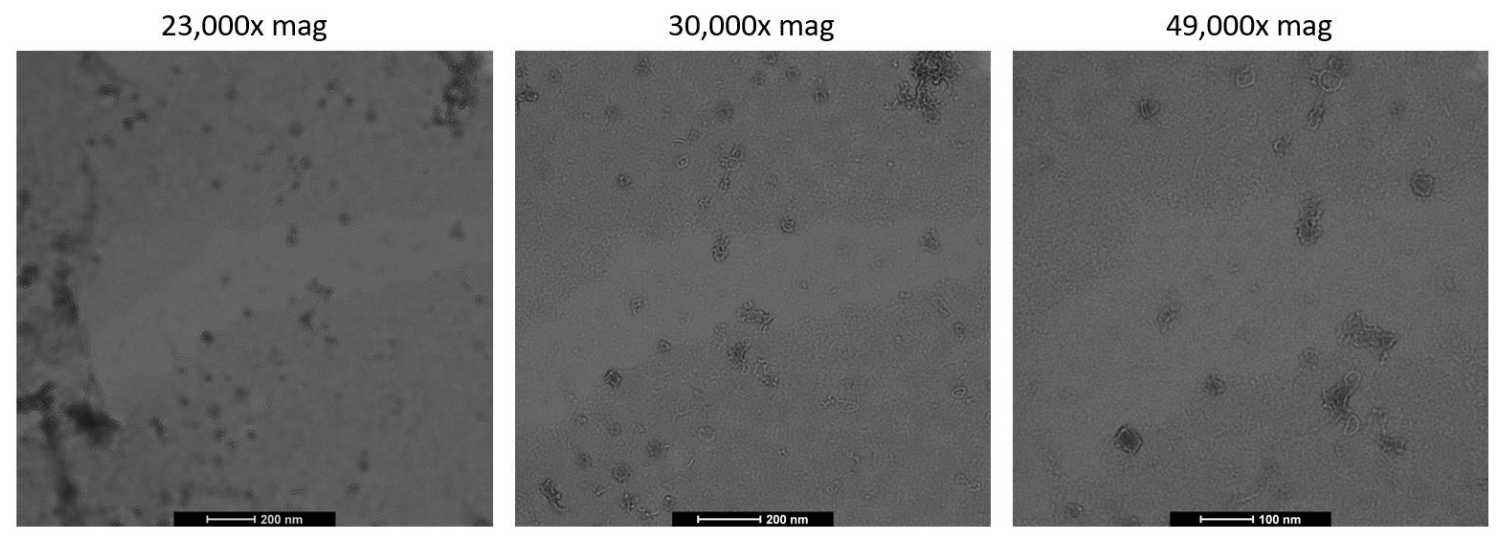

Figure S9. Ultrastructural characterization of assembly using 18-mer DNA-PL4 scaffolds. 
Henrich et al., SI to accompany J. Am. Chem. Soc. manuscript ja-2019-00651b.RI

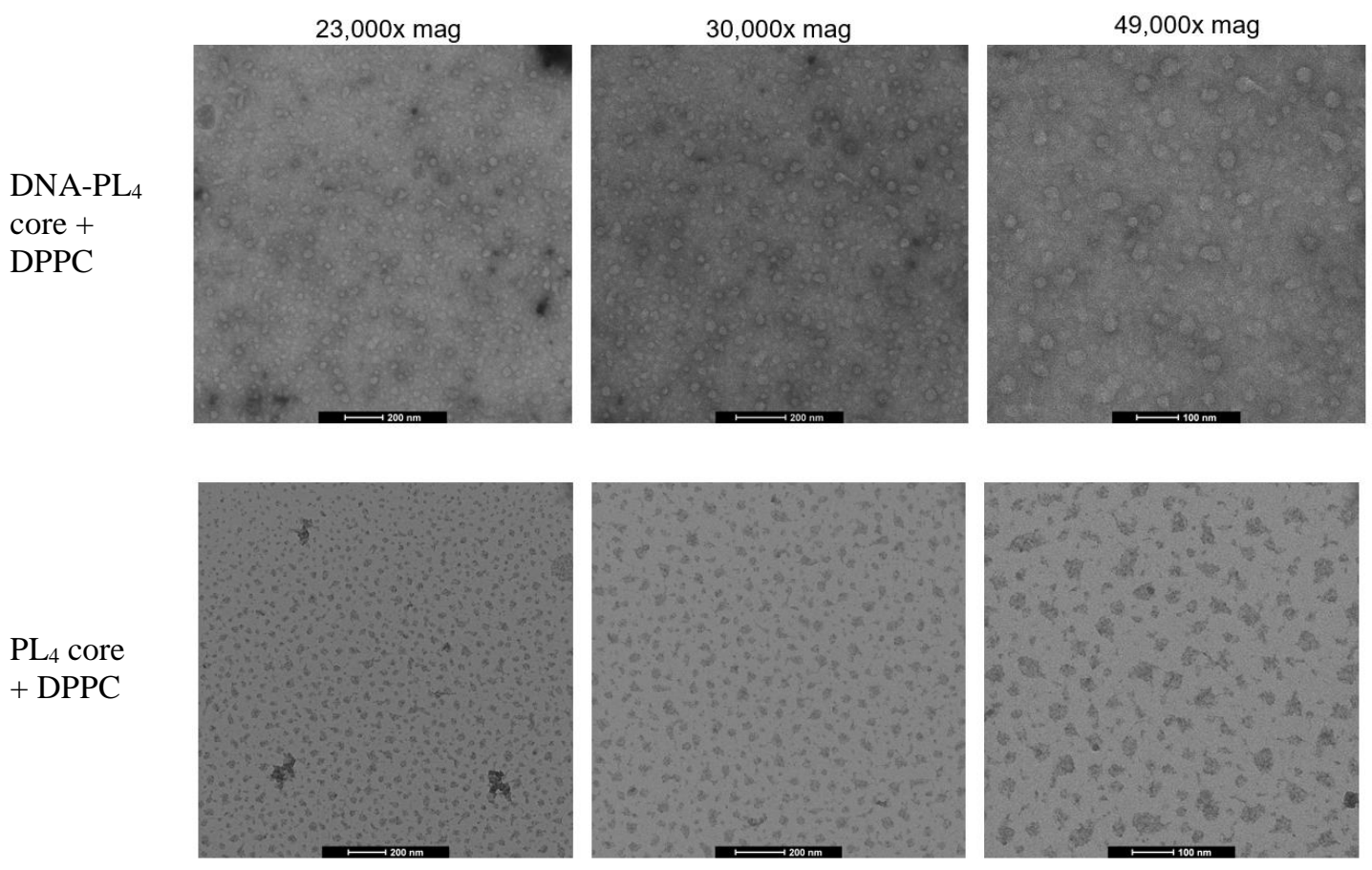

Figure S10. TEM imaging of core scaffolds + DPPC control samples, in the absence of apoA-I. We note that DNAcontaining samples and non-DNA-containing samples have differential propensities for uptake of uranyl acetate stain.
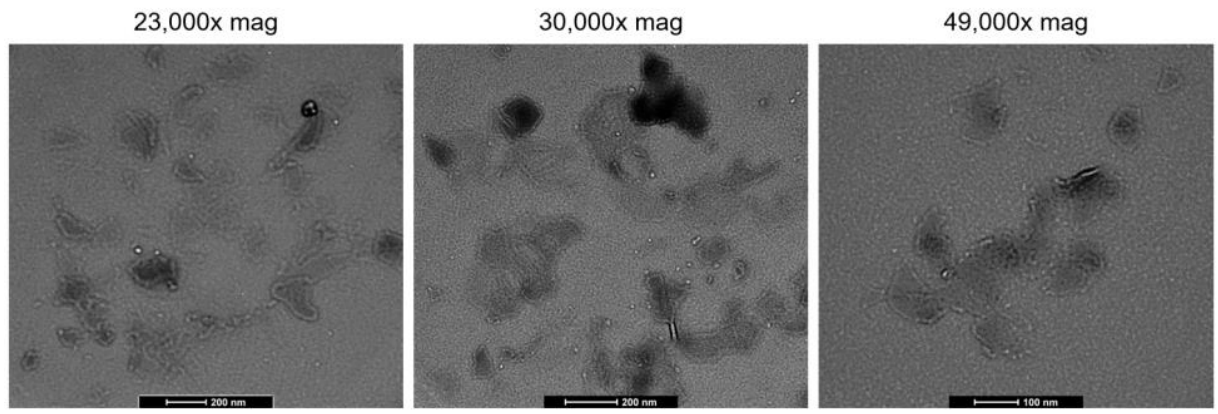

Figure S11. TEM imaging of apoA-I + DPPC control assembly in the absence of a lipid-conjugated core scaffold. 


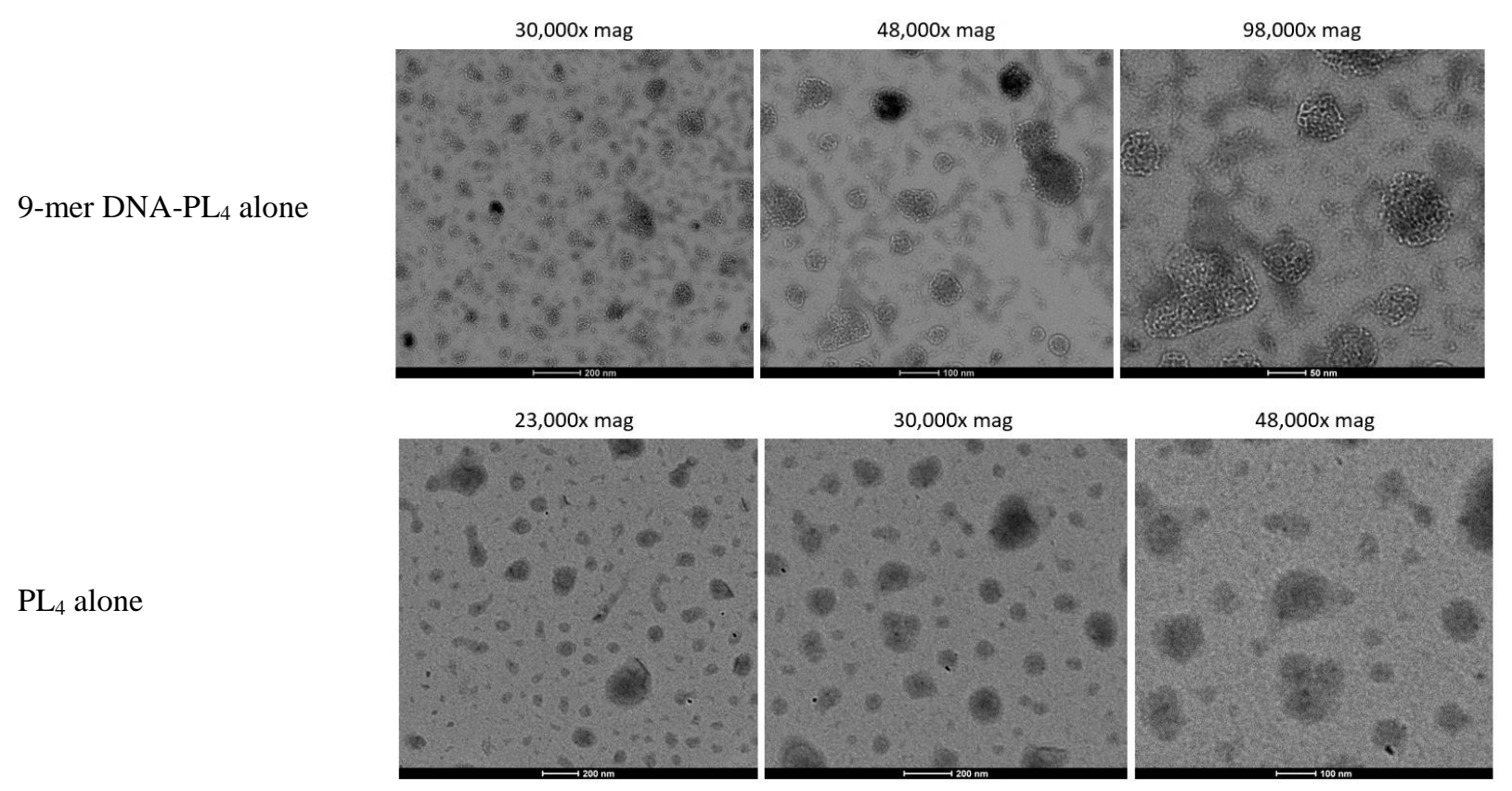

Figure S12. TEM images of core scaffolds alone, without DPPC or apoA-I. Both core scaffolds form large vesicular structures that are $\sim 50-200 \mathrm{~nm}$ in diameter, resembling liposomes. Most pertinent to this work, they do not form small particles in the size regime observed for LC HDL NPs. We note that DNA-containing samples and non-DNA-containing samples have differential propensities for uptake of uranyl acetate stain.

\section{b. apoA-I immunoblot of LC HDL NPs for detection of apoA-I oligomers}

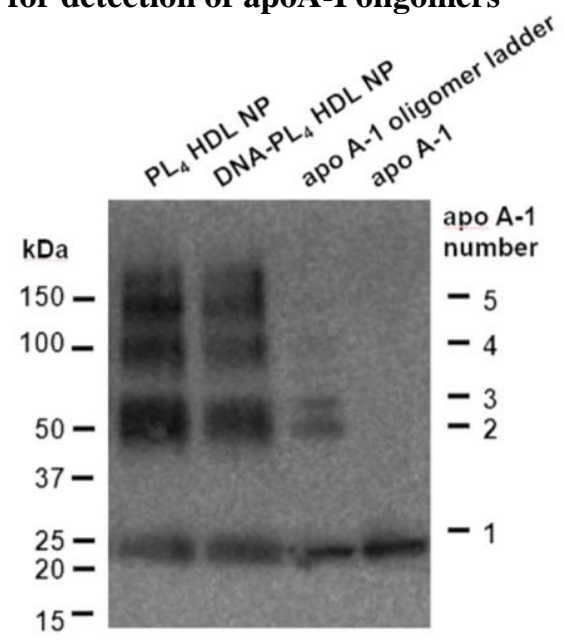

Figure S13. Characterization of LC HDL NP assembly and apoA-I oligomerization profiles. apoA-I adopts higher order oligomerization states upon assembly with lipid conjugate core scaffolds for both $\mathrm{PL}_{4}$ and DNA-PL4 particles.

c. Dynamic light scattering results for LC HDL NPs and controls.

Table S2. Hydrodynamic diameters of LC HDL NPs and controls determined by dynamic light scattering.

\begin{tabular}{lc}
\hline \multicolumn{1}{c}{ Sample } & Hydrodynamic Diameter $(\mathrm{nm})$ \\
\hline Free apoA-I & $7.6 \pm 0.2$ \\
Human HDL & $14.1 \pm 5.0$ \\
Human $\mathrm{HDL}_{3}$ & $13.6 \pm 6.1$ \\
$\mathrm{PL}_{4} \mathrm{HDL}_{\mathrm{NP}}$ & $13.8 \pm 3.9$ \\
DNA-PL $_{4} \mathrm{HDL}$ NP & $13.3 \pm 4.6$ \\
\hline
\end{tabular}


Henrich et al., SI to accompany J. Am. Chem. Soc. manuscript ja-2019-00651b.RI

d. Size-exclusion chromatography (SEC) analysis of LC HDL NPs and controls.

Table S3. Retention volumes for LC HDL NPs and controls from size-exclusion chromatography.

\begin{tabular}{|c|c|}
\hline Sample & Peak Retention Volume (mL) \\
\hline Free apoA-I & 10.13 \\
\hline Human $\mathrm{HDL}_{2}$ & 8.21 \\
\hline Human $\mathrm{HDL}_{3}$ & 8.26 \\
\hline $\mathrm{PL}_{4} \mathrm{HDL} N \mathrm{NP}$ & 8.88 \\
\hline DNA-PL $_{4} \mathrm{HDL}_{\mathrm{NP}}$ & 8.22 \\
\hline DNA-PL 4 scaffold alone & 6.33 \\
\hline apoA-I + DPPC (no scaffold) & 6.98 \\
\hline
\end{tabular}

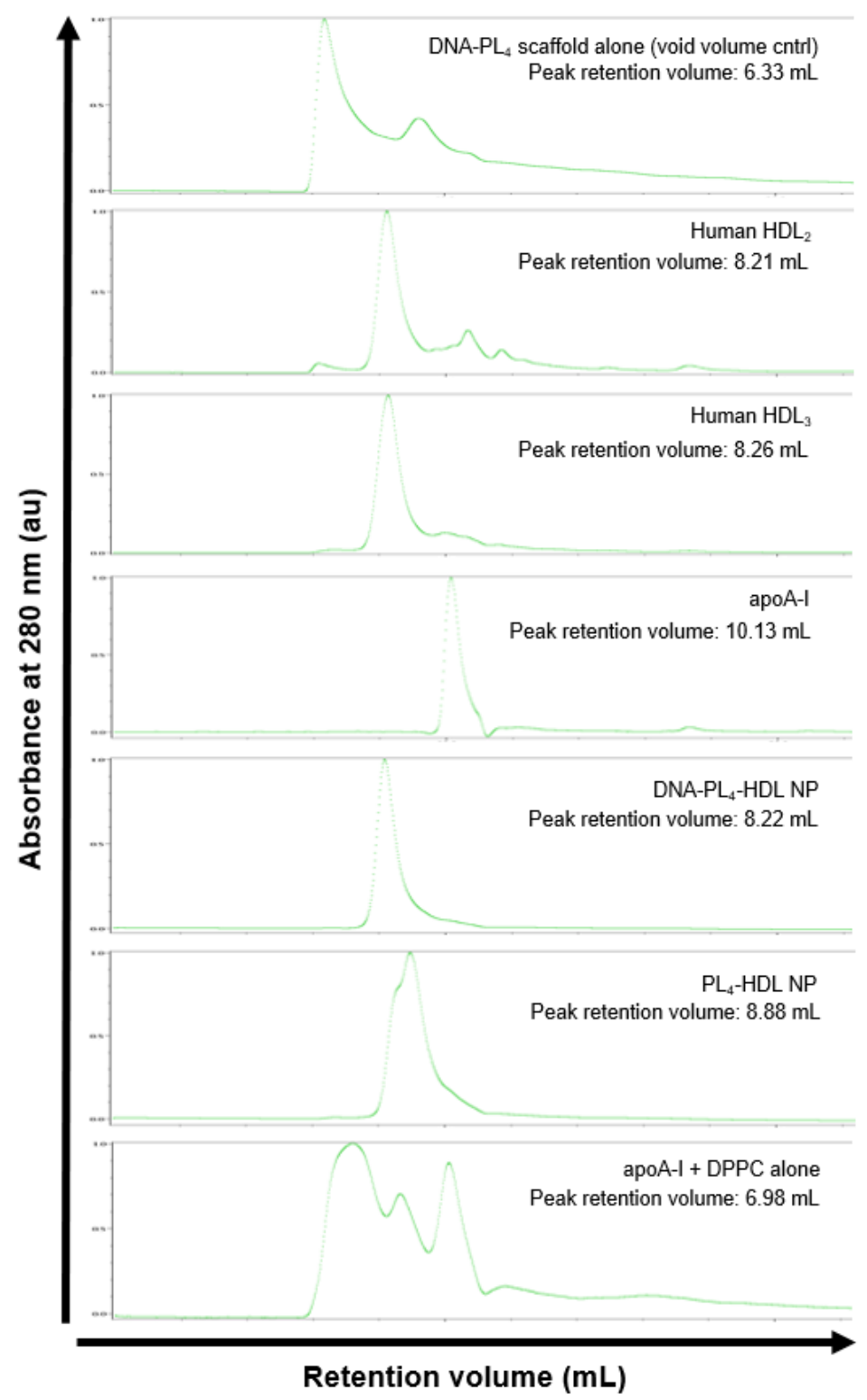

Figure S14. Size exclusion chromatography results for LC HDL NPs and controls. UV-vis absorbance at $280 \mathrm{~nm}$ (arbitrary units) is plotted on the $\mathrm{y}$-axis against retention volume $(\mathrm{mL})$ on the $\mathrm{x}$-axis. 


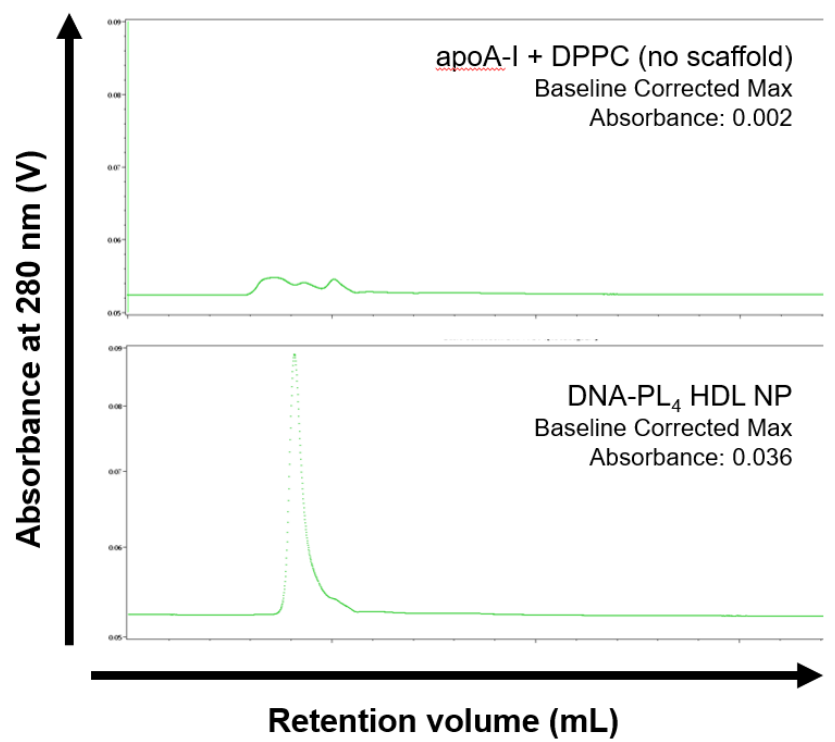

Figure S15. Size exclusion chromatography results for apoA-I + DPPC (no scaffold) control and DNA-PL 4 HDL NP. The raw (non-normalized) UV-vis absorbance at $280 \mathrm{~nm}(\mathrm{~V})$ is plotted on the y-axis against the retention volume $(\mathrm{mL})$ on the $\mathrm{x}$-axis. Samples were prepared at identical protein concentrations $(1 \mathrm{mg} / \mathrm{mL})$ prior to filtration with a $0.2 \mu \mathrm{m}$ filter for SEC analysis.

In the remainder of this section, we offer a brief discussion of our interpretations of the SEC data shown above. First, we used two different control samples with large hydrodynamic diameters to determine the void volume: 1) The DNA-PL4 scaffold alone, which exhibited diameters between 100 and $200 \mathrm{~nm}$ via TEM, and 2) Collagen IV, a large extracellular matrix protein ( $160 \mathrm{kDa}$; predicted to be trimerized in aqueous solution). Both samples (Figure S14 for the SEC trace of DNA$\mathrm{PL}_{4}$ scaffold alone; data not shown for Collagen IV) began to elute from the SEC column at $\sim 6.0 \mathrm{~mL}$, which we define as the "void" (i.e., not-retained) volume. The SEC trace for the DNA-PL 4 scaffold alone also exhibited a small peak at $9.28 \mathrm{~mL}$, which likely represents monomers or low-molecular-weight oligomers of the core scaffold.

The SEC traces for PL 4 HDL NPs and DNA-PL 4 HDL NPs exhibited peaks with retention volumes of 8.88 and $8.22 \mathrm{~mL}$, respectively, compared to those in the SEC traces for the human $\mathrm{HDL}_{2}$, human $\mathrm{HDL}_{3}$, and apoA-I controls $(8.21,8.26$, and $10.13 \mathrm{~mL}$, respectively). Notably, while the eluted SEC peak for the DNA-PL 4 HDL NPs appear to be unimodal, the PL4 HDL NPs exhibited two overlapping elution peaks $(8.58-8.88 \mathrm{~mL}$ retention volume) that can be attributed to particles with different numbers of apoA-I copies (i.e., 2-3 vs 4-5, see SI, Section S11f2 for discussion). The SEC traces for both LC HDL $\mathrm{NP}$ samples also exhibited small right-sided tails consistent with the presence of a small amount of free apoA-I $(\sim 10.13 \mathrm{~mL})$. This is not surprising as excess apoA-I was used in the assemblies. We note that this free apoA-I protein peak was also observed in the trace for the native HDL controls (Figure S14).

We also subjected an [apoA-I + DPPC] mixture without a core scaffold to SEC analysis as a control and observed a heterogenous mixture of large, intermediate, and small species (Figure S14). Notably, this [apoA-I + DPPC] control sample appears to have assembled primarily into large protein aggregates, as the vast majority of protein ( $95 \%)$ was found to have been lost upon filtration with a $0.2 \mu \mathrm{m}$ filter, a required operation to protect the SEC column. Even the fraction of materials that passed through the filter ( $5 \%$ protein) appeared to consist of a polydisperse mixture of large structures, apoA-I alone, and intermediate-size particles from SEC analysis (Figure S15). These SEC results reveal that a large portion of the [apoAI + DPPC] sample elutes in the void, with additional heterogeneous populations eluting continuously between 6 and 12 minutes, resulting in a significant tail at longer retention times.

In sum, our SEC results support data from the other size characterization methods (TEM and DLS) in suggesting that LC HDL NPs are within the size regimes of native HDLs.

\section{e. Composition of LC HDL NPs.}

Table S4. Molar composition ratios for $\mathrm{PL}_{4}$ HDL NPs and DNA-PL 4 HDL NPs.

\begin{tabular}{lccc}
\hline \multicolumn{1}{c}{ Sample } & $\begin{array}{c}\text { apoA-I/core scaffold } \\
(\mathrm{mol} / \mathrm{mol})\end{array}$ & $\begin{array}{c}\text { DPPC/core scaffold } \\
(\mathrm{mol} / \mathrm{mol})\end{array}$ & $\begin{array}{c}\text { DPPC/apoA-I } \\
(\mathrm{mol} / \mathrm{mol})\end{array}$ \\
\hline PL $_{4}$ HDL NP & -- & $89^{*}$ & 35 \\
DNA-PL 4 HDL NP & 2.56 & 54 & 21 \\
\hline
\end{tabular}

*Calculated using the protein/core scaffold ratio experimentally determined for DNA-PL $\mathrm{HDL} \mathrm{NPs}_{4}$. 


\section{f. Supplemental discussions}

f1. On the likelihood of the particles possessing a surface monolayer of phospholipids versus a bilayer, we offer the following calculations. We consider both the possibility of an interdigitated bilayer, as well as a conventional, tail-to-tail bilayer. For a spherical particle with a diameter of $9 \mathrm{~nm}$ (i.e., as determined by TEM), the surface area of the outer leaflet is $4 \pi \mathrm{r}^{2}=4 \pi(4.5 \mathrm{~nm})^{2}=254 \mathrm{~nm}^{2}$. This estimate for the outer leaflet applies to both interdigitated and conventional bilayers. For an ideal interdigitated bilayer, with a thickness of $20 \AA$, the inner leaflet of a $9 \mathrm{~nm}$ diameter particle would have a radius of $2.5 \mathrm{~nm}$ and a surface area of $79 \mathrm{~nm}^{2}$. Therefore, if we assume that a hydrated phospholipid head group has a surface area of $\sim 0.72 \mathrm{~nm}^{2},{ }^{7}$ the particle would require approximately 463 lipids/particle to form an interdigitated bilayer, excluding the surface area contribution of apoA-I on the particle. If we allow for apoA-I to assume $50 \%$ of the particle surface (a generous estimate), the particles would require approximately 232 phospholipids to form a bilayer over the remaining surface. If instead we consider a monolayer model, we then predict $~ 176$ phospholipids/particle. The latter estimate is much closer to the ratios we observed experimentally. For a non-interdigitated, tail-to-tail bilayer with bilayer thickness of $40 \AA{ }^{8}{ }^{8}$ the radius of the inner leaflet layer would be extremely small, at just $0.5 \mathrm{~nm}$. Such structures have never been observed at these size scales, and are predicted to be extremely unfavorable due to the highly strained curvature that would be required for such an assembly. ${ }^{9-10}$

In fact, if we assume that there is only one core scaffold per particle, our experimentally determined composition values are below the expected number of phospholipids required for a monolayer, further reducing the likelihood of a bilayered particle. We therefore believe that either apoA-I occupies a greater portion of the particle surface on average than expected (plausible given the oligomerization results), and/or that some fraction of the particles contains more than one core scaffold. If we assume an average of two core scaffolds per particle, we obtain estimates of 106-180 phospholipids per particle, which are consistent with the estimate calculated above for a monolayer.

We note that the aforementioned calculations use the diameter of LC HDL NPs as determined via TEM. The SEC results, for instance in the case of $\mathrm{PL}_{4}$ HDL NPs (see discussions at the end of Section S11d above and in Sections S11f2 and S11f5 below), indicate that one could change the numbers of constituents (e.g., the number of apoA-I copies per particle) or include other components to account for other populations of particles. Additionally, the aforementioned calculations also neglect any perturbations to the outer phospholipid layer, which may be introduced by the externally oriented lipid tails from PL 4 and DNA-PL 4 scaffolds. These perturbations would then increase the effective surface area per phospholipid (i.e., $>0.72 \mathrm{~nm}^{2}$ ), which would move the estimated number of phospholipids/particle even lower than the aforementioned estimate for a monolayer, which would trend even more toward our experimentally determined data, and away from a bilayer model. Independently of these calculations, Yetukuri et. al. estimates 109 phospholipids per native human HDL particle. ${ }^{11}$ This is directly in the vicinity of our molar composition data, assuming an average of 1-2 cores per particle. While the back-of-theenvelope calculations provided above constitute a cursory examination of particle composition as it relates to our proposed model, future studies could be devoted to computational simulations with atomic-level precision in order to determine particle structure more precisely.

f2. Regarding the apoA-I copy number per particle, the cross-linking results presented in Figure S13 reveal the highestintensity bands for particles with 2-3 apoA-I molecules, with significant presence of bands for particles with 4-5 copies. This data is consistent with the best models of human HDL available, for instance in Figures 5 and 6 of a manuscript by Huang et. al. ${ }^{12}$ These figures illustrate models in which apoA-I is arranged in HDLs in trimers, tetramers, and pentamers in various conformations.

f3. We offer the following discussion regarding the validity of comparing phospholipid composition between synthetic and native HDLs using our quantification methods, and whether the outputs of the colorimetric assays that we used are reflective of total HDL composition. The commercially available phospholipid quantification assay we used relies on detection of choline moieties. While native HDLs harbor a diverse range of phospholipids, non-phosphatidylcholine lipids comprise quite a small minority of HDL lipid content by mass or mol \%. For instance, Yetukuri et al. ${ }^{11}$ report the following data for human HDL in non-pathological conditions:

Table S5. Molar composition of native HDLs. ${ }^{11}$

\begin{tabular}{llllllll} 
& apoA-I & Sphingomyelins & $\begin{array}{l}\text { Phosphatidyl } \\
\text { Choline }\end{array}$ & $\begin{array}{l}\text { Free } \\
\text { Cholesterol }\end{array}$ & $\begin{array}{l}\text { Cholesteryl } \\
\text { Esters }\end{array}$ & Triglycerides & $\begin{array}{l}\text { Lyso- } \\
\text { PC }\end{array}$ \\
\hline Copy \# & 2 & 19 & 109 & 50 & 90 & 19 & 10 \\
\hline
\end{tabular}

Given this data, we calculate that by quantifying PC and lyso-PC using the choline detection kit, and free cholesterol and cholesteryl esters using the Amplex Red assay, we will on average account for 259/297 lipid molecules in a typical native HDL particle. Furthermore, our protein quantification method is unbiased as bicinchoninic acid does not discriminate between 
the exclusive apoA-I harbored by LC HDL NPs vs the combination of apoA-I ( 70\%), apoA-II ( 20\%), and non-apoA proteins in native HDLs, and will therefore detect all proteins present in both synthetic and native samples. Consequentially, the quantification methods we used for composition studies account for the overwhelming majority of lipids and proteins in native and synthetic HDLs in an unbiased fashion.

f4. In this section, we provide the following working-hypothesis regarding the mechanism of action for cholesterol transport by DNA-PL ${ }_{4}$ HDL NPs: DNA-PL ${ }_{4}$ HDL NPs diffuse through the aqueous biological medium and bind to the HDLspecific, cell surface receptors (ABCA1, ABCG1, SR-B1) via the apoA-I proteins on their surfaces. Upon binding to the receptor, these particles induce a conformational change in the receptor whereby cholesterol is mobilized from the plasma membrane through a non-aqueous pore in the receptor and onto the particle. The non-esterified, effluxed cholesterol forms constructive enthalpic interactions with the hydrophobic portions of the apoA-I protein and the phospholipid tail groups of the monolayer on the particle surface, while the alcohol group may interact with the negatively charged DNA moiety or the phospholipid head groups via hydrogen bonding. After sequestering the effluxed cholesterol, the particles eventually dissociate from the receptor and diffuse back into the medium.

When LCAT is present, the apoA-I proteins on the particle serve as co-factors for the enzymatic esterification of the sequestrated cholesterol. When the particle-bound cholesterol molecules become esterified, the hydrophobic portion of the cholesteryl esters may reorient preferentially toward hydrophobic residues on apoA-I and phospholipid tails. Another possibility is that after esterification, some of the cholesteryl ester is transferred from the DNA-PL 4 HDL NPs to other lipoproteins in solution (e.g., via CETP).

For delivery function, DNA-PL 4 HDL NPs loaded with cholesterol can engage the SR-B1 receptors on the surface of hepatocytes, and transfer cholesterol into these cells via a non-aqueous pore in the receptor. A single cohort of DNA-PL4 HDL NPs may be able to on-load and off-load cholesterol for multiple rounds of efflux and delivery.

For $\mathrm{PL}_{4}$ HDL NPs, the core is hydrophobic and can therefore theoretically sequester cholesteryl esters quite efficiently. We demonstrated that this is likely the case via the LCAT esterification assay shown in Figure 5a in the main manuscript, where these particles harbor significantly more cholesteryl esters than their DNA-PL 4 counterparts. In contrast, the DNA$\mathrm{PL}_{4} \mathrm{HDL}$ NP is less likely to pack as many cholesteryl esters into its core, given the hydrophilic nature of the DNA-containing scaffold and the packing of the core (see Section S11f5 below). Thus, it may be that the DNA-PL 4 HDL NPs can efficiently efflux free cholesterol and pack some unesterified cholesterol into the particle, but not a large quantity of cholesteryl esters, as suggested by Figure 5a.

f5. In this section, we provide a rough estimate of the size of the DNA-PL4 scaffold and provide some insights into whether this scaffold is surrounded by a phospholipid mono- or bilayer, assuming that the average particle size is 9-14 nm.

We estimate that a single arm of the DNA-PL 4 scaffold is $\sim 6 \mathrm{~nm}$ in length, and hence that the diameter of the DNA-PL 4 scaffold, if all four arms were fully extended, would be $\sim 12 \mathrm{~nm}$. We arrive at these estimates from the following values for each component: 1) 9-mer DNA length is $\sim 3 \mathrm{~nm}$, since there are approximately 3 bp per $1 \mathrm{~nm}, 2$ ) phospholipid length is $2 \mathrm{~nm}$ according to prior reports, and 3) a single arm of the tetrahedral small molecule scaffold is about $1 \mathrm{~nm}$ based on bondlength estimates. As the DNA-PL 4 scaffold likely folds in on itself to maximize packing, the diameter of the scaffold may be reduced to $\sim 6-8 \mathrm{~nm}$ prior to assembly with phospholipids and apoA-I protein.

Next, the phospholipids bound to the particle surface are modeled as a monolayer based upon the following assumptions: 1) that phospholipids will not form a bilayer in particles with very small size and highly curved surfaces, such as one with a diameter as small as $10 \mathrm{~nm}, 2$ ) that our particle adopts a native HDL structure, and 3) that our TEM results show an annular hypodense region that appears to be the external lipid layer. Regarding the last assumption, this external layer is approximately $2 \mathrm{~nm}$ in thickness, which is consistent with a lipid monolayer, as opposed to a bilayer $(\sim 4 \mathrm{~nm})$. Thus, we suggest that the lipid layer in our HDL NPs is in fact a monolayer. If apoA-I is then bound and adsorbed to the particle surface, it would be embedded in the surface lipid layer and does not significantly increase the $2 \mathrm{~nm}$ monolayer thickness.

Taken together, the aforementioned estimates would yield a particle diameter in the 9-14 $\mathrm{nm}$ range, consistent with our experimental data. We note that favorable interactions between the lipid tails, apoA-I, and the DNA may further contract the particle somewhat so as to minimize any molecular dead space.

\section{S12. References}

1. Pandey, P.; Farha, O. K.; Spokoyny, A. M.; Mirkin, C. A.; Kanatzidis, M. G.; Hupp, J. T.; Nguyen, S. T., A "click-based" porous organic polymer from tetrahedral building blocks. J. Mater. Chem. 2011, 21 (6), 1700-1703.

2. Chan, Y. H.; van Lengerich, B.; Boxer, S. G., Lipid-anchored DNA mediates vesicle fusion as observed by lipid and content mixing. Biointerphases 2008, 3 (2), FA17.

3. Hong, B. J.; Eryazici, I.; Bleher, R.; Thaner, R. V.; Mirkin, C. A.; Nguyen, S. T., Directed Assembly of Nucleic Acid-Based Polymeric Nanoparticles from Molecular Tetravalent Cores. J. Am. Chem. Soc. 2015, 137 (25), 8184-8191.

4. Zhao, Y.; Imura, T.; Leman, L. J.; Curtiss, L. K.; Maryanoff, B. E.; Ghadiri, M. R., Mimicry of high-density lipoprotein: functional peptide-lipid nanoparticles based on multivalent peptide constructs. J. Am. Chem. Soc. 2013, 135 (36), 13414-24.

5. Luthi, A. J.; Lyssenko, N. N.; Quach, D.; McMahon, K. M.; Millar, J. S.; Vickers, K. C.; Rader, D. J.; Phillips, M. C.; Mirkin, C. A.; Thaxton, C. S., Robust passive and active efflux of cellular cholesterol to a designer functional mimic of high density lipoprotein. J. Lipid Res. 2015,56 (5), $972-85$. 
Henrich et al., SI to accompany J. Am. Chem. Soc. manuscript ja-2019-00651b.R1

6. Stock, R. S.; Ray, W. H., Interpretation of photon correlation spectroscopy data: A comparison of analysis methods. J. Polym. Sci., Polym. Phys. Ed. 1985, 23 (7), 1393-1447.

7. $\quad$ Melcrova, A.; Pokorna, S.; Pullanchery, S.; Kohagen, M.; Jurkiewicz, P.; Hof, M.; Jungwirth, P.; Cremer, P. S.; Cwiklik, L., The complex nature of calcium cation interactions with phospholipid bilayers. Sci. Rep. 2016, 6.

8. Mitra, K.; Ubarretxena-Belandia, I.; Taguchi, T.; Warren, G.; Engelman, D. M., Modulation of the bilayer thickness of exocytic pathway membranes by membrane proteins rather than cholesterol. Proc. Natl. Acad. Sci. U.S.A. 2004, 101 (12), 4083-8.

9. Lin, C. M.; Li, C. S.; Sheng, Y. J.; Wu, D. T.; Tsao, H. K., Size-dependent properties of small unilamellar vesicles formed by model lipids. Langmuir 2012, 28 (1), 689-700.

10. Hong, B. J.; Iscen, A.; Chipre, A. J.; Li, M. M.; Lee, O. S.; Leonard, J. N.; Schatz, G. C.; Nguyen, S. T., Highly Stable, Ultrasmall PolymerGrafted Nanobins (usPGNs) with Stimuli-Responsive Capability. J. Phys. Chem. Lett. 2018, 9 (5), 1133-1139.

11. Yetukuri, L.; Soderlund, S.; Koivuniemi, A.; Seppanen-Laakso, T.; Niemela, P. S.; Hyvonen, M.; Taskinen, M. R.; Vattulainen, I.; Jauhiainen, M.; Oresic, M., Composition and lipid spatial distribution of HDL particles in subjects with low and high HDL-cholesterol. J. Lipid Res. 2010, 51 (8), 234151 .

12. Huang, R.; Silva, R. A. G. D.; Jerome, W. G.; Kontush, A.; Chapman, M. J.; Curtiss, L. K.; Hodges, T. J.; Davidson, W. S., Apolipoprotein A-I structural organization in high-density lipoproteins isolated from human plasma. Nat. Struct. Mol. Biol. 2011, 18 (4), 416-U44. 